\title{
Anaerobic oxidation of methane in differences types of geological structures at Lake Baikal
}

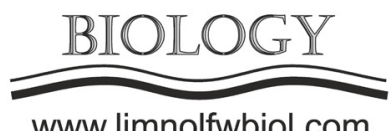

www.limnolfwbiol.com

\author{
Lomakina A.V. ${ }^{1 *}$, Bukin S.V. ${ }^{1}$, Pogodaeva T.V. ${ }^{1}$, Ivanov V.G. ${ }^{1}$, Khalzov I.A. ${ }^{1}$, \\ Krylov A.A. ${ }^{1,2,3}$, Zemskaya T.I. ${ }^{1}$ \\ ${ }^{1}$ Limnological Institute, Siberian Branch of the Russian Academy of Sciences, Ulan-Batorskaya Str., 3, Irkutsk, 664033, Russia \\ ${ }^{2}$ FGBU "Academician I.S. Gramberg All-Russia Research Institute for Geology and Mineral Resources of the World Ocean" \\ (VNIIOkeangeologia), St. Petersburg, Russia \\ ${ }^{3}$ Institute of Earth Sciences, St. Petersburg State University, St. Petersburg, Russia
}

\begin{abstract}
Although in sediments of Lake Baikal process of anaerobic oxidation methane was revealed by radioisotope techniques, by of the methane profile we know a little about the microorganisms carrying out this process. Here we studied diversity of archaeal communities in different types geological structures (methane seeps and mud volcano) on Lake Baikal with different composition of pore waters and the discharged fluid. In investigate were used different methods molecular biology including of high-throughput sequencing of gene 16S rRNA and PCR analysis different genes of AOM ( $m c r A)$. Molecular analysis did not reveal methane-oxidizing archaea ANME-1, -2, or -3, which are responsible for anaerobic oxidation of methane in marine sediments. Hydrogenotrophic methanogenic archaea representatives of the orders Methanomicrobiales, Methanococcales, as well as acetoclastic methanogens of the order Methanosarsinales were abundant in a mud volcano at Lake Baikal. In investigation sites we found divers M. nitroreducens-like archaea (ANME-2d subcluster) both in deep sediments of a methane seeps and in a mud volcanoes. Their closest homologues involved in process anaerobic oxidation of methane in different freshwater systems, bioreactors, paddy field soils.
\end{abstract}

Keywords: Lake Baikal, microbial community, anaerobic oxidation methane, Archaea, ANME-2d, mcrA

\section{Introduction}

Lake sediments are globally important carbon stores, but they are also important contributors of methane $\left(\mathrm{CH}_{4}\right)$ (Bastviken et al., 2004). Approximately $70 \%$ of atmospheric methane is of microbial origin. Anaerobic oxidation of methane (AOM) reduces methane emissions from marine ecosystems but we know little about AOM in freshwater reservoir. The most studied processes are sulfate-dependent methane oxidation via the reverse methanogenesis pathway performed by archaea of the ANME clusters in marine sediments (Knittel and Boetius, 2009). In recent years, there has been an active search for microbial agents that carry out AOM in freshwater ecosystems. Recent studies have shown that in oxygen-free soil layers and bottom sediments oxidation of methane provide anaerobic methanotrophic bacteria and/or archaea, which can use as electron acceptors nitrate, nitrite and metal oxides. This is members of the archaeal family Methanoperedenaceae, formerly known as ANME-2d subclusters, and representatives Candidatus Methylomirabilis oxyfera (known as NC10 bacteria) (Ettwig et al., 2010; Haroon et al., 2013).
Lake Baikal has unique characteristics and phenomena observed in its ecosystem and processes are noted in both freshwater and marine ecosystems. The unique characteristics of Lake Baikal include the presence in its sediments of gas hydrate (GH). Their formation is understandable, since as shown in the works of Namsaraev et al. (1995), Dagurova et al. (2004), Pimenov et al. (2014), methane generation is the main final process of destruction of organic matter in Baikal. And the low temperatures and deep sea of the lake ensure their formation and preservation. Another feature of the lake is the presence of autigenic carbonates in its deep sediments. These problems are related, since carbonates are confined to areas where there is discharge of hydrocarbon fluids (Krylov et al., 2008). On Lake Baikal describes more than 50 geological structures that differ in the composition of the discharged fluids (Khlystov et al., 2018). In the composition of the discharged fluid can presence ions of sulfate, nitrate, ammonium, acetate, iron, hydrocarbonate, increased concentrations of which are detected in the bottom sediments of the sites of Southern and Central Baikal (Zemskaya et al., 2015; Lomakina et al., 2020). Pore water of sediment Lake 
Baikal are often rich in Fe and Mn (up to 240 and 95 $\mu \mathrm{M}$, respectively), and in all deep basins of Lake Baikal the occurrence of cm-thick layers of Fe and Mn oxides buried within the reducing part of the sediments is well known (e.g. Granina et al., 2004; Och et al., 2012; Zemskaya et al., 2018). In deep sediments near GH, the rate of methane oxidation ranged from 35 to $273.2 \mu \mathrm{l}$ $\mathrm{CH}_{4} /\left(\mathrm{dm}^{3}\right.$ day) (Dagurova et al., 2004), increasing at depths of 20-60 cm, which may indicate the functioning of the anaerobic community of microorganisms (Zemskaya et al., 2010). Process of AOM in deep sediments of Lake Baikal was revealed by radioisotope techniques, with the maximum that was usually close to the GH layers, as well as by of the methane profile (Zemskaya et al., 2010). Our investigation showed that in deep sediments of sites gas-oil containing fluids the process of AOM carried out by representatives ANME-2d subclusters and NC10 (Lomakina et al., 2018; 2020). ANME-2d archaea may play an important role in controlling methane emissions from nitratedepleted and low-sulfate freshwater systems (Weber et al., 2017). Molecular analysis of Baikal sediments did not reveal methane-oxidizing archaea ANME-1, -2, or -3 , which are responsible for anaerobic oxidation of methane in marine sediments (Lomakina et al., 2018; 2020). Sediment from associated with oil, GH, in addition to authigenic carbonates of Southern and Central Baikal, were collected and analyzed with 16S rRNA and mcrA gene phylogenetic data. These results establish baseline data for future AOM studies at Lake Baikal and elucidate metabolic pathways this process, as well as and electron acceptors.

\section{Materials and methods}

The materials for the study were sediments samples from expedition (2010, 2012, 2016, 2019) on board the research vessel (RV) "G.Yu. Vereshchagin". Samples of bottom sediments were collected from geomorphologically distinct sites: the mud volcano Malenky ( 1371 water depth) Kedr $(\sim 600 \mathrm{~m})$, the methane seep Posolsk Bank (PB, 400 m) and Krasny Yar $(\sim 730 \mathrm{~m})$. Layers of methane hydrates occurred in the sediments of the mud volcano Malenky (130-131, 132$139 \mathrm{~cm}$ ) and sediments of the methane seep Posolsk Bank $(100 \mathrm{~cm}, 140 \mathrm{~cm})$. In samples of sediments the mud volcano Kedr $(127-130 \mathrm{~cm}, 125-127 \mathrm{~cm}, 150-$ $152 \mathrm{~cm})$ and Malenky (145 cm) detected authigenic carbonates. After lifting the core onto the RV board and cutting it into two lengthwise halves, the sediment samples were collected for chemical analysis of pore waters and DNA extraction. Chemical analysis of pore waters was carried out on board immediately after sampling. Sediments selected for DNA extraction were stored in liquid nitrogen until the laboratory analysis. For further analysis and investigation were selected samples containing GHs (Malenky 130-131 cm, 132$139 \mathrm{~cm}$; Posolsk Bank $100 \mathrm{~cm}, 140 \mathrm{~cm}$ ), authigenic carbonates (Malenky 140-146 cm, Kedr $127-130 \mathrm{~cm}$, $125-127 \mathrm{~cm}, 150-152 \mathrm{~cm}$ ) and oxidized channel in bottom sediment of mud volcano Krasny Yar (35-37 $\mathrm{cm})$.
DNA was extracted according to phenolchloroform alcohol method. PCR amplification with primers on the archaeal (V5-V7 region) 16S rRNA gene fragments were carries out.

Analysis of the similarity of the 16S rRNA gene sequences to the known GenBank sequences (http:// www.ncbi.nlm.nih.gov/genbank/) was carried out using the BLAST software package. Corresponding phylogenetic trees were constructed by the $\mathrm{NJ}$ and Kimura two-parameter methods implemented in MEGA version 6.0 .

\section{Results and discussion}

This study examined samples of deep sediments from different type's geological structures at Lake Baikal. Sediments of the investigated core from a methane seep Posolsk Bank were highly saturated with gas. Methane concentration increased with depth (up to $10 \mu \mathrm{M}$ in surface sediments), reaching maximum values (up to $9000 \mu \mathrm{M}$ ) in the sedimentary strata where GHs were detected. Throughout the core, there were increased concentrations of $\mathrm{CH}_{3} \mathrm{COO}^{-}$ions up to $379 \mu \mathrm{M}$ and $\mathrm{Fe}^{2+}$ up to $134 \mu \mathrm{M}$. Concentration ion of $\mathrm{NO}_{3}^{-}$was $20 \mu \mathrm{M}$ in surface sediments, and it was not detected in other pore waters, as well as concentrations of $\mathrm{SO}_{4}^{2-}$ ions had maximum values in the surface sediments ( 62 $\mu \mathrm{M})$. Unlike the methane seep Posolsk Bank, methane concentrations in sediments of a methane seep Krasny Yar not exceeded $190 \mu \mathrm{M}$ in the surface and $500 \mu \mathrm{M}$ in depth sediments. Ions $\mathrm{Fe}^{2+}, \mathrm{Mn}^{2+}, \mathrm{NH}_{4}^{+}, \mathrm{NO}_{2}^{-}$, and $\mathrm{CH}_{3} \mathrm{COOH}^{-}$in pore waters were absent. Sulfate was detected in pore water only in the uppermost interval of sediments $(0-50 \mathrm{~cm})$ and at very low concentration up to $60 \mu \mathrm{m}$.

In deep sediments of a mud volcano Malenky concentration of methane exceeded $90 \mu \mathrm{M}$ almost from the surface and showed uneven distribution with the maximum value at a depth of $140 \mathrm{~cm}$ (up to 1200 $\mu \mathrm{M})$. The concentrations of $\mathrm{SO}_{4}^{2-}$ in pore waters of the investigated core reached $3781 \mu \mathrm{M}$ in sediments that contained carbonate $(140-146 \mathrm{~cm})$; the minimum concentrations were recorded in GH layers (130-131 $\mathrm{cm}$ and 132-139 cm). Higher concentrations of $\mathrm{HCO}_{3}$ ions in comparison with the reference values (up to $1098 \mu \mathrm{M})$ are typical of all studied sediments with the maximum in GH layer of $130-131 \mathrm{~cm}$ (up to $4049 \mu \mathrm{M}$ ). Nitrate and acetate were not detected in the pore water (Lomakina et al., 2020).

The concentration of $\mathrm{SO}_{4}{ }^{2-}$ in pore waters a mud volcano Kedr varied from $56 \mu \mathrm{M}$ in surface sediments to $52 \mu \mathrm{M}$ in the deep sediments. The concentrations of $\mathrm{Fe}^{2+}$ reached $3.5 \mu \mathrm{M}, \mathrm{Mn}^{2+} 11.4 \mu \mathrm{M}$. Nitrate ions presented in all investigation sediments with concentration 9.1 $\mu \mathrm{M}$ in surface layer and $6.6 \mu \mathrm{M}$ in the deep sediments. Acetate was not detected in the pore water of Kedr. Maximum value of methane was fixed in deep sediments (to $1138 \mu \mathrm{M}$ ), in surface layer concentration methane not reached $9.8 \mu \mathrm{M}$.

The studied sites differed in composition of dominated archaeal communities. So, analysis of $16 \mathrm{~S}$ rRNA gene libraries showed that in sediments of a mud 
volcano Malenky the dominant phyla were sequences of Bathyarchaeota (12\%, 54\% in GH layers), Euryarchaeota (99\% in carbonate layer; 27\%, 35.7\%), Crenarchaeota (17\%, 25\% in GH layers). Nucleotide sequences of phylum Thaumarchaeota dominated (up to $20 \%$ of all $16 \mathrm{~S}$ rRNA reads) only one of GH layer $(130-131 \mathrm{~cm})$. In the composition of bottom sediments from a methane seep Posolsk Bank, Euryarchaeota (60\%, 95\% of all 16S rRNA reads) dominated. Representatives of Bathyarchaeota (27\%), Crenarchaeota (10\%) were presented only in layer $100 \mathrm{~cm}$. In the oxidized channel Euryarchaeota (45\%), Bathyarchaeota (28\%), Woesearchaeota (14\%), Crenarchaeota (6.5\%), Thaumarchaeota (2.7\%). Among archaea dominated phyla were Bathyarchaeota (3876\%), Euryarchaeota (5-33\%) at all investigation sediments of a mud volcano Kedr. Archaea of phyla Nanoarchaeota, Vestraetearchaeota were detected in bottom layers of a mud volcano Kedr. Previously, nucleotide sequences of these phyla were not detected in other of the discharged fluids sites. In addition, representatives of phylum Vestraetearchaeota know as methilotrophic methanogens (Vanwonterghem et al., 2016).

In result of phylogenetic analysis members of the know archaea (ANME-1, -2 and -3 clusters) performed AOM were not found. Analysis nucleotide sequences of gene 16S rRNA showed the presence of ANME-2d subcluster. However, representatives of this subcluster were absent in GHs sediments of site Posolsk Bank, but abundant in carbonate layers of a mud volcanoes (9\% in site Kedr, and $20 \%$ of all 16 S rRNA sequences from site Malenky), GH sediments of a mud volcano Malenky, as well as in oxidized channel a methane seep Krasny Yar (to $3.5 \%$ of all $16 \mathrm{~S}$ rRNA reads Archaea). The nucleotide sequences of ANME-2d obtained in this study were similar to the sequences from different environments, including Lake Ørn sediments, freshwater iron-enriched microbial mat, coal-rich sediments.

We tested all recovered DNA samples for $m c r A$ genes of the ANME-2d subcluster. The analysis of the obtained translated amino acid sequences has confirmed the presence of $m c r A$ genes of the ANME-2d in the communities. The analysed amino acid sequences of the bottom sediments investigated areas were similar to $m c r A$ gene sequences of $M$. nitroreducens (ANME2d). Sequences from sediments Lake Baikal were closest relatives from the microbial mat of Hydrate Ridge North, Pacific Ocean; bioreactor, in which AOM processes, occurred together with iron reduction.

\section{Conclusion}

Our studies showed that despite the different chemical composition of pore waters, as well as the composition of the dispersing fluids this does not affect the distribution of the dominant archaea phyla. In studied sites were found representatives of methane oxidizing archaea ANME-2d subcluster, but no marine ANME clusters. However, diversity methanogenic archaea is characterized by a significant variety of sequences than methanotropic archaea (ANME-2d).

\section{Acknowledgments}

This work was carried out within the framework of the State Assignment no. 0345-2019-0007 (expedition studies) and was supported by the Russian Science Foundation, project no. 19-17-00226 (study of site Kedr), and by the Russian Foundation for Basic Research, project no. 18-04-00244_a (study of sites Malenky, Posolsk Bank, Krasny Yar).

\section{References}

Bastviken D., Cole J., Pace M. et al. 2004. Methane emissions from lakes: dependence of lake characteristics, two regional assessments, and a global estimate. Global Biogeochemical Cycles 18. DOI: 10.1029/2004GB002238

Dagurova O.P., Namsaraev B.B., Kozyreva L.P. et al. 2004. Bacterial processes of the methane cycle in bottom sediments of Lake Baikal. Microbiology 74: 248-257. (in Russian)

Ettwig K.F., Butler M.K., Le Paslier D. 2010. Nitritedriven anaerobic methane oxidation by oxygenic bacteria. Nature 464: 543-548. DOI: 10.1038/nature08883

Granina L., Muller B., Wehrli B. 2004. Origin and dynamics of $\mathrm{Fe}$ and $\mathrm{Mn}$ sedimentary layers in Lake Baikal. Chemical Geology 205: 55-72. DOI: 10.1016/j.chemgeo.2003.12.018

Haroon M.F., Hu S., Shi Y. et al., 2013. Anaerobic oxidation of methane coupled to nitrate reduction in a novel archaeal lineage. Nature 500: 567-570. DOI: 10.1038/ nature 12375

Khlystov O.M., Khabuev A.V., Minami H. et al. 2018. Gas hydrates in Lake Baikal. Limnology and Freshwater Biology 1: 66-70. DOI: 10.31951/2658-3518-2018-A-1-66

Knittel K., Boetius A. 2009. Anaerobic oxidation of methane: progress with an unknown process. Annual Review Microbiology 63: 311-334. DOI: 10.1146/annurev. micro.61.080706.093130

Krylov A.A., Minami H., Hachikubo A. et al. 2008. Crystallization of authigenic carbonates in mud volcanoes at Lake Baikal. Geochemistry International 46: 985-995. DOI: 10.1134/S0016702908100030

Lomakina A.V., Mamaeva E.V, Galachyants Y.P. et al. 2018. Diversity of Archaea in bottom sediments of the discharge areas with oil- and gas-bearing fluids in Lake Baikal. Geomicrobiology Journal 35: 50-63. DOI: 10.1080/01490451.2017.1315195

Lomakina A., Pogodaeva T., Kalmychkov G. et al. 2020. Diversity of NC10 Bacteria and ANME-2d Archaea in sediments of fault zones at Lake Baikal. Diversity-Basel 12: 10. DOI: $10.3390 / \mathrm{d} 12010010$

Och L.M., Muller B., Voegelin A. et al. 2012. New insight into the formation and burial of $\mathrm{Fe} / \mathrm{Mn}$ accumulations in Lake Baikal sediments. Chemical Geology 330-331: 244-259. DOI: 10.1016/j.chemgeo.2012.09.011

Pimenov N.V., Zakharova E.E., Bryukhanov A.L. et al. 2014. Activity and structure of the sulfate-reducing bacterial community in the sediments of the southern part of Lake Baikal. Microbiology 83: 47-55. DOI: 10.1134/ S0026261714020167

Namsaraev B.B., Dulov L.E., Sokolova E.N. et al. 1995. Bacterial formation of methane in bottom sediments of Lake Baikal. Microbiology 64: 411-417. (in Russian)

Vanwonterghem I., Evans P.N., Parks D.H. et al. 2016. Methylotrophic methanogenesis discovered in the archaeal phylum Verstraetearchaeota. Nature Microbiology 1. DOI: 10.1038/nmicrobiol.2016.170

Weber H.S., Habicht K.S., Thamdrup B. 2017. Anaerobic methanotrophic archaea of the ANME-2d cluster are active 
in a low-sulfate, iron-rich freshwater sediment. Frontiers in Microbiology 8. DOI: 10.3389/fmicb.2017.00619

Zemskaya T.I., Lomakina A.V., Mamaeva E.V. et al. 2015. Bacterial communities in sediments of Lake Baikal from areas with oil and gas discharge. Aquatic Microbial Ecology 76: 95-109. DOI: 10.1134/S0026261714030126

Zemskaya T.I., Pogodaeva T.V., Shubenkova O.V. et al. 2010. Geochemical and microbiological characteristics of sediments near the Malenky Mud Volcano (Lake Baikal, Russia), with evidence of archaea intermediate between the marine anaerobic methanotrophs ANME-2 and ANME-3. Geo-Marine Letters 30: 411-425. DOI: 10.1007/ s00367-010-0199-6

Zemskaya T.I., Lomakina A.V., Mamaeva E.V. et al. 2018. Composition of microbial communities in sediments from Southern Baikal containing Fe/Mn concretions. Microbiology 87: 382-392. DOI: 10.1134/S0026261718030165 